\title{
The Implication in Foreign Language Teaching at Colleges Based on Language Attrition and Memory Features
}

\author{
Zhang Yuhuan ${ }^{1, \text { a }}$ \\ ${ }^{1}$ School of Foreign Languages, China West Normal University, China \\ ajuliezhyh@163.com
}

Keywords: Language attrition; Memory features; Students at colleges; Implication

\begin{abstract}
This paper displays an overview of language attrition theory and principles of memory. At the meanwhile, it regards college students' memory features as the breakthrough point in order to interpret the implication in foreign language teaching based on language attrition, combined with the reality of college English teaching in our country.
\end{abstract}

\section{Introduction}

Since the reform and opening up, great changes have taken place in our foreign language education: foreign language education has developed quickly and it also has made significant and remarkable achievements. The one undisputed fact is that most of English learners in our country start learning English since their junior middle school and last until their college life, but some of them start English from their primary school, even some from their kindergarten. Learning English has last as long as ten years, but people usually can hear complaints from students: "I have learned English for ten years, but what is English?" "How can I learn English well?" "Since the college entrance examination, what I had learned about English has returned to English teacher...." What causes to such phenomena is language attrition because English teaching in our country puts more attention to cultivation of English skills and abilities but neglects the maintenance of English language proficiency in the condition of lacking target language environment. This thesis intends to interpret the implication of foreign language learners' English maintaining ability from the standpoint of language attrition, which regards memory features as breakthrough point and combines the reality of foreign language teaching at colleges. Accordingly, it causes to English teachers' deep thought about how to maintain foreign language learners' English abilities.

\section{Related Definition and Researches}

Language attrition describes the phenomenon on the loss of or the stagnation of language knowledge or foreign language skills because of declining use or no use of the language after second language or foreign language teaching with time going by. Language attrition is not an abrupt language loss and stagnation phenomenon but a gradual language phenomenon.

According to the attrition of different languages and the different environments where attrition happens, van Els[1] divides language attrition into four kinds: L1 in a L1 environment (Type 1), L1 in a L2 environment (Type 2), L2 in a L1 environment (Type 3) and L2 in a L2 environment (Type 4). When it comes to English attrition in Chinese context, such foreign language attrition falls into L2 in a L1 environment (Type 3) in the situation of lacking English register but Chinese register.

Early in 1980s, foreign scholars has set about doing researches on language attrition, working Conference on the attrition of language skills in University of Pennsylvania as the landmark. Since then, more and more researchers in foreign countries have made attribution to language attrition. Compared with the materials on language attrition abroad, domestic materials are not so abundant. Until 2000s, language attrition has begun to attract researchers' attention at home, but most of them focus on literature review of language attrition and displayed the factors related with language attrition and implication in foreign language in foreign teaching in our country. In our country, English learning has the typical characteristic of high input and low output, so it is worth of being 
beneficial to do studies on language attrition in order to maintain their comprehensive abilities of using English.

Memory is the reflection of past experience in the brain, including the four stages of memorization, maintenance, recognition and reproduction.[2] According to the length of maintenance, memory can be divided into instantaneous memory, short-term and long-term memory. Instantaneous memory refers to unprocessed raw material but the storage and effectiveness of short-term memory is so limited, while long-term memory can last forever. In other words, the space of long-term memory is endless. As a result, when instantaneous memory and short-term memory are transferred into long-term memory by way of information input and information encoding, information can be stored forever and it is difficult to attrite. To some degree, forgetting can be thought as a way of attrition. It means recognition and reproduction of recited materials or making mistakes in recognition and reproduction. Gaining external stimuli, people try to pay much attention to such stimuli, transform it into short-term memory and review it in time, which can cause to long-term memory; therefore, it can be recognized and reproduced completely in extracting information. Gardner thought that the critical period of language attrition usually takes place in the incubation time of language knowledge.[4] the incubation time refers to the time between the end time of foreign language courses and the start time of foreign language proficiency. The time is the critical time of language knowledge and skills maintenance, so it is necessary for people to grasp time and chances to use the language and review it in order to prevent language attrition from happening.

\section{The Features of College Students' Memory}

Memorization is a basic method of accumulating experience and enriching knowledge and prerequisite of college students' psychological development. The features of college students' memory development are as the following:[5] one is that logical memory ability is improved significantly. Psychological study shows that a person's logical memory ability can achieve the highest peak during the age of from 20 to 25, but most of college students during their whole college life fall into the age scope. With more extensive subjects to learn, more difficulty of subject matter which is abstract and improved learning quality standard, college students' logical memory ability can be developed quickly and greatly. Thus, they have the capacity to analyze the meaningful materials and summarize the meaningful and valuable new knowledge experience to recite; moreover, they can store what they have learned about new knowledge into their existing knowledge system by way of processing and filtering; what they can recite is mastered knowledge after analyzing or knowledge which cannot be understood. Another feature is various memory qualities have gotten all-around development. College students are at the best age and in the golden period of memory, because their agility, persistence, precision and accuracy, etc. about memory have evolved. More about college students is that they have grasped many practical and valid memory methods. Meanwhile, college students learn a foreign language after they have grasped their mother language. Because the encoding of languages is similar, it is much easier for college students to gain another language. Throughout the history of college foreign language teaching, foreign language education has gained many achievements, but it is common that there exist some college students who cannot speak English after many years of learning it. It is worthwhile for college English teachers to apply to effective teaching methods to stop language attrition.

\section{Implication in Foreign Language Teaching}

Since college students in the golden time of memory, can recited materials be arbitrary and random? According to the whole language proficiency of college students, the answer is negative. College foreign language teachers should follow the scientific principles of memory, explore the method which can be used to rein texts and design exploratory items which can guide college students to enter scientific and exploratory situations to discover new knowledge. Then they can become a detector or creator, experiencing the joy of success and arousing their study motivation. College students can get 
enjoyable and educational English-learning experience. Foreign language teaching can also yield twice the result with half the effort.

English teachers put more stimuli and strengthen language stimuli for college students in the incubation time of knowledge. Language attrition takes place quickly at the beginning and then gradually slowly and language attrition starts from vocabulary. College students want to consolidate their learning efficiency; they have to review what they have learned before language attrition happens. Stimulus-response theory points out that new knowledge can be consolidate at the time when it is learned; if people decline uses of the language or stop using the language, connecting power of old and new knowledge is weakening and their related knowledge gradually disappear. Generally speaking, once people have finished learning new knowledge, they had better input more related knowledge, using time longer and interval shorter; with memory consolidated, the using time of language is shorter, interval longer.

English teachers intend to eliminate interference factors on language attrition for college students in the incubation time of knowledge. Wu Xinchun [6] points out interference includes two types: one is proactive inhibition and the other is retroactive inhibition. The former means what people have learned before interferes with memorization and reminiscence of what they would have learned. The latter means what people have learned later interferes with maintenance and reminiscence of what they had learned. When other conditions are the same, people learn items at the beginning and at the end quicker and better, items in the middle slower and worse. Perhaps the better results at the beginning and at the end is because such materials have gotten less interference factors. College students touch more information which can distract them, so their language attrition takes place not because of lapses in memory but too many interference factors. As a result, English teachers are familiar with such interference factors which make college students' language attrition appear, making efforts to help students exclude the difficulty and anxiety to remove their learning disabilities in order to make their learning achievements.

English teachers improve initiatives and increase motivation for college students in the incubation time of knowledge to avoid language attrition. People always can recall happy things happening in the past. When foreign language learning becomes a torture, college students intentionally leaves their informational memory of foreign language out of consciousness. The completeness of language-stored task depends on language learners' initiatives and positivity, which rests with their consciousness and need of tasks. If college students lack high demand of learning English, they would be short of initiatives and enthusiasm; but their initiatives have a close connection with acquaintance and experience of foreign language learning. Therefore, foreign language teachers know about college students' learning motivation in their teaching activities and guide their college students experience the joy of success of learning a foreign language, which can arouse college students' interest and give full play to the initiative and creativity of learning English.

\section{Conclusion}

The factors related with language attrition and language acquisition make language factors which can influence language attrition various and complex, but language attrition is unable to be neglected in the process of foreign language learning. Once they stop learning English, language attrition begins to take place because college students in China learn a foreign language in the situation of lacing relating language. Simply relying on foreign language teaching workers' strength is not enough because stopping language attrition happening is a systematic project. It also requires foreign language learners to continue to learn and review the foreign language to avoid language attrition. Moreover, foreign language teachers should explore real-time method and teaching method holding back language attrition, which can make researches on language attrition have more practical significance and researching value. 


\section{References}

[1] Van Els, T. (1986). An Overview of European Research on Language Attrition. Language Attrition in Progress. The Netherlands Foris Publication.

[2] Gong Weiyi\& Liu Xinmin. (2004).Developmental psychology. Beijing: Beijing Science and Technology Press.

[3] Wang Naiming \& Qian Feng. (2006). Preschool Psychology. Shanghai: Fudan University Press.

[4] Li Ping\& Zheng Shutang (2004). Language loss and retainment. Shandong Foreign Language Teaching, (5).

[5] Wu Xinchun. (1999). Higher Education Psychology. Beijing: High Education Press. 